\title{
Introduction to Entrepreneurship and Knowledge Management Minitrack
}

\author{
Katia Passerini \\ St. John's University \\ passerik@stjohns.edu
}

\author{
Michael R. Bartolacci \\ Penn State University - Berks \\ mrb24@psu.edu
}

\begin{abstract}
This minitrack reflects the intersection of two key areas in business research: entrepreneurship and knowledge management (KM). Although at first glance, the two may not appear to be highly interrelated, they have a profound impact on one another.
\end{abstract}

\section{Introduction}

Entrepreneurship can be explained as a unique style of management in which a few key business players create and expand a business through a loose managerial structure that focuses on increased revenue streams, market creation and expansion. The hectic nature of start-ups makes it difficult for innovators to spend time on the collection of key business knowledge throughout the entire entrepreneurship process. Entrepreneurs generally fast track from ideating, pivoting through launching, rather than pausing on codifying and accumulating knowledge. The innovation stage is swift and exciting, and calls for organizational agility. To be successful at this stage, especially in highly technical and competitive industries, the knowledge of the entrepreneur is better kept "secret" through patents and trademarks.

This is in contradiction with the typical KM goals of codifying and transferring knowledge and, as such, the accumulation of explicit knowledge becomes an unexciting activity that slows down creation and implementation. Explicit knowledge sharing may not be considered a high priority by entrepreneurs.

This track reviews the link between knowledge management and entrepreneurial activities and identifies some interesting trends in this domain, with a focus on emerging technology, digital entrepreneurship equity and diffusion, and the tech entrepreneurs' relationships with knowledge creation.

The manuscripts in this mini-track highlight some important trends. In the paper "A Qualitative Evaluation of IoT-driven eHealth: Knowledge Management, Business Models and Opportunities,
Deployment and Evolution," Lokshina and Lanting discuss provide a qualitative evaluation of IoT-driven eHealth from theoretical and practical viewpoints by looking at knowledge management issues and contributions of IoT to eHealth. The authors look at this domain from a variety of knowledge-focused point of views and conclude that for IoT driven eHealth to happen timely and securely, a bigger alignment between information technology developments and medical practices needs to take place before the accessibility benefits of electronic and remote health can be brought to fruition.

Chandran and Aleidi's study "Analyzing the Influence of Gender Stereotypes and Social Norms on Female IT Entrepreneurial Intention in Saudi Arabia" presents a comprehensive literature review uncovering that innovation, technology and female entrepreneurs are rarely discussed in the same context. The research examines the relationship between gender stereotypes and social norms on women's IT entrepreneurial intention and decisionmaking processes that lead women to become tech entrepreneurs in Saudi Arabia. They conclude that understanding women's IT entrepreneurial intention can provide guidance on actual entrepreneurial behaviors and launch of IT startups.

Finally, Bandera, Keshtkar, and Passerini review a well-known $\mathrm{KM}$ model in a paper entitled "Internalization among Technology Entrepreneurs: Looking to the Future While Grounded in the Past." Based on linguistic analysis of interviews with entrepreneurs, they show that internalization (i.e., the creation of tacit knowledge from explicit assets) plays an important role in new ventures activities. The paper finds a strong relationship between an entrepreneur's references to the past and the number of employees in the venture, indicative of the importance of an entrepreneur's prior knowledge internalization and learning as a driver of the growth and success of the current venture.

This track contributes to the growing field of entrepreneurial knowledge management by analyzing the role of KM in fostering start-ups success and their sustainability. 